\title{
Non-surgical interventions for paediatric pes planus (Review)
}

\author{
Rome K, Ashford RL, Evans A
}

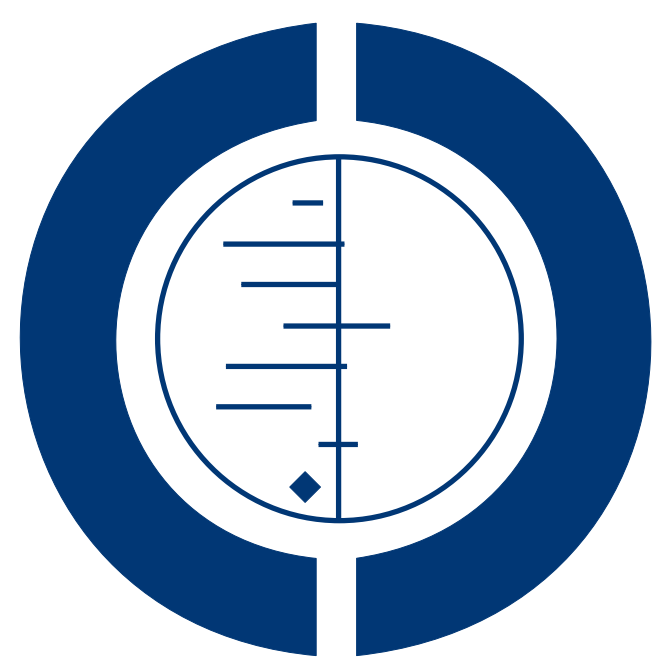

\section{THE COCHRANE COLLABORATION $^{\circledR}$}

This is a reprint of a Cochrane review, prepared and maintained by The Cochrane Collaboration and published in The Cochrane Library 2010, Issue 7

http://www.thecochranelibrary.com

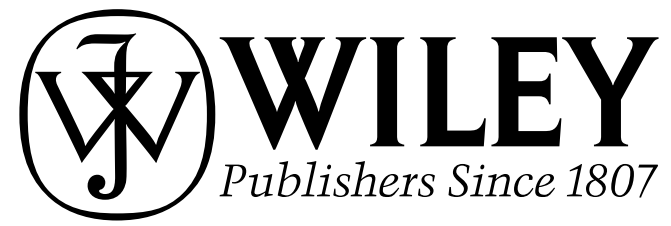

Non-surgical interventions for paediatric pes planus (Review)

Copyright (C) 2010 The Cochrane Collaboration. Published by John Wiley \& Sons, Ltd. 
TABLE OF CONTENTS

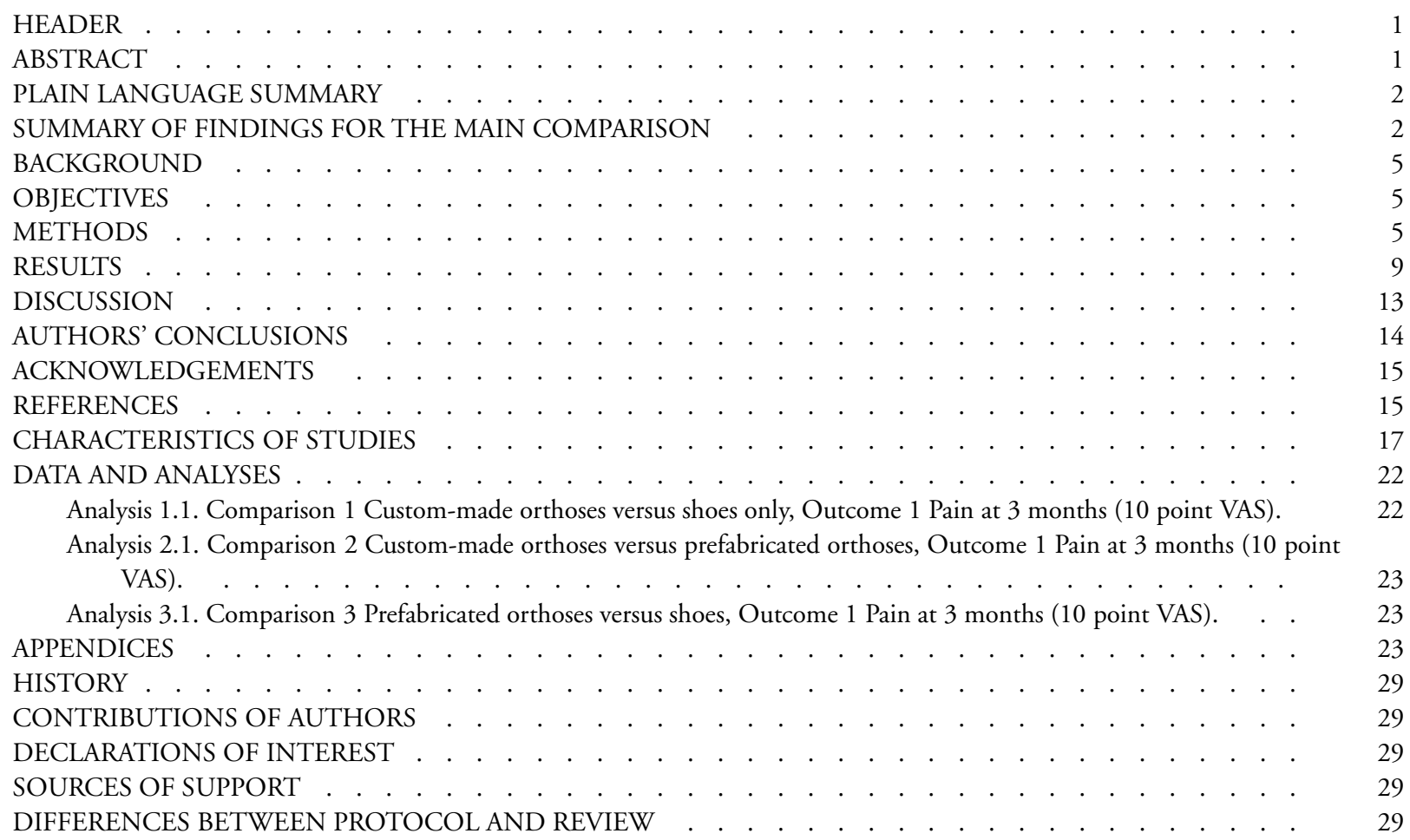

Non-surgical interventions for paediatric pes planus (Review)

Copyright (C) 2010 The Cochrane Collaboration. Published by John Wiley \& Sons, Ltd. 


\title{
[Intervention Review]
}

\section{Non-surgical interventions for paediatric pes planus}

\author{
Keith Rome ${ }^{1}$, Robert L Ashford ${ }^{2}$, Angela Evans ${ }^{3}$ \\ ${ }^{1}$ Division of Rehabilitation \& Occupation Studies, AUT University, Auckland 1020, New Zealand. ${ }^{2}$ Faculty of Health and Community \\ Care, Birmingham City University, Birmingham, UK. ${ }^{3}$ School of Health Science (Podiatry), University of South Australia, Adelaide, \\ Australia \\ Contact address: Keith Rome, Division of Rehabilitation \& Occupation Studies, AUT University, Akoranga Drive, Private Bag 92006, \\ Auckland 1020, New Zealand. krome@aut.ac.nz.
}

Editorial group: Cochrane Musculoskeletal Group.

Publication status and date: New, published in Issue 7, 2010.

Review content assessed as up-to-date: 15 December 2009.

Citation: Rome K, Ashford RL, Evans A. Non-surgical interventions for paediatric pes planus. Cochrane Database of Systematic Reviews 2010, Issue 7. Art. No.: CD006311. DOI: 10.1002/14651858.CD006311.pub2.

Copyright (C) 2010 The Cochrane Collaboration. Published by John Wiley \& Sons, Ltd.

\section{A B S T R A C T}

\section{Background}

Paediatric pes planus ('flat feet') is a common childhood condition with a reported prevalence of $14 \%$. Flat feet can result in pain and altered gait. No optimal strategy for non-surgical management of paediatric flat feet has been identified.

\section{Objectives}

To assess the effectiveness of non-surgical interventions for treatment of paediatric pes planus (flat feet).

\section{Search strategy}

We searched the Cochrane Central Register of Controlled Trials (CENTRAL) (The Cochrane Library), MEDLINE, EMBASE, CINAHL, Index to Theses, and Dissertation Abstracts (up to June 2009).

\section{Selection criteria}

All randomised and quasi-randomised trials of non-surgical interventions for paediatric pes planus were identified. The primary outcomes were pain reduction and adverse events; secondary outcomes included disability involving the foot, goniometric measurements, quality of life and patient comfort.

\section{Data collection and analysis}

Two authors independently extracted data and assessed the risk of bias of included trials.

\section{Main results}

Three trials involving 305 children were included in this review. Due to clinical heterogeneity, data were not pooled. All trials had potential for bias. Data from one trial (40 children with juvenile arthritis and foot pain) indicated that use of custom-made orthoses compared with supportive shoes alone resulted in significantly greater reduction in pain intensity (mean difference (MD) -1.5 points on a 10-point visual analogue scale (VAS), 95\% CI -2.8 to -0.2; number need to treat to benefit (NNTB) 3, 95\% CI 2 to 23 ), and reduction in disability (measured using the disability subscale of the Foot Function Index on a $100 \mathrm{~mm}$ scale (MD $-18.65 \mathrm{~mm}, 95 \%$ CI -34.42 to $-2.68 \mathrm{~mm})$. The second trial of seven to 11 year old children with bilateral flat feet $(\mathrm{n}=178)$ found no difference in the number of participants with foot pain between custom-made orthoses, prefabricated orthoses and the control group who received no treatment. A third trial of one to five year olds with bilateral flat feet $(n=129)$ did not report pain at baseline but reported the subjective impression of pain reduction after wearing shoes. No adverse effects were reported in the three trials. 


\section{Authors' conclusions}

The evidence from randomised controlled trials is currently too limited to draw definitive conclusions about the use of non-surgical interventions for paediatric pes planus. Future high quality trials are warranted in this field. Only limited interventions commonly used in practice have been studied and there is much debate over the treatment of symptomatic and asymptomatic pes planus

\section{PLAIN LANGUAGE SUMMARY}

\section{Non-surgical interventions for flat feet in children}

This summary of a Cochrane review presents what we know from research about the effect of non-surgical treatments for pes planus (flat feet) in children.

The review shows that in children with flat feet and juvenile idiopathic arthritis, custom foot orthoses:

-may improve pain and function slightly

-harms and side effects were not measured

We often do not have precise information about side effects and complications. This is particularly true for rare but serious side effects.

\section{What are flat feet and what are non-surgical treatments?}

Children with flat feet, also called pes planus, do not have a normal arch. It means that when the child is standing, the whole foot touches the ground. Sometimes, this condition can cause pain, or change the way a child walks.

There are many types of non-surgical treatments for the pain and disability caused by flat feet such as foot orthoses (shoe inserts), stretching, footwear selection and modifications, activity modifications, manipulation, applying a series of casts, losing weight (if appropriate) and medication for pain and inflammation.

This review found information mainly on custom foot orthoses or shoe inserts. A custom foot orthosis is a medical device that is made from a custom mould of the child's foot, prescribed by a qualified health-care professional and which is designed by that professional to allow more normal foot and leg function and to decrease the pressure on parts of the foot that might be causing pain.

Best estimate of what happens to children with flat feet:

Pain:

-children who used a custom-made foot orthoses in their shoes rated their pain to be 1.5 on a scale of 0-10;

-children who wore their shoes only rated their pain to be 3 on a scale of $0-100$;

-children who used a custom-made foot orthoses in their shoes rated their pain to be 1.5 points better (Absolute improvement: 15\%).

Physical Function:

-children who used a custom-made foot orthoses in their shoes rated their disability level to be 15 on a scale of 0-100;

-children who wore their shoes rated their disability to be 34 on a scale of $0-100$;

-children who used a custom-made foot orthoses in their shoes rated their disability to be 19 points better (Absolute improvement: $19 \%)$. 


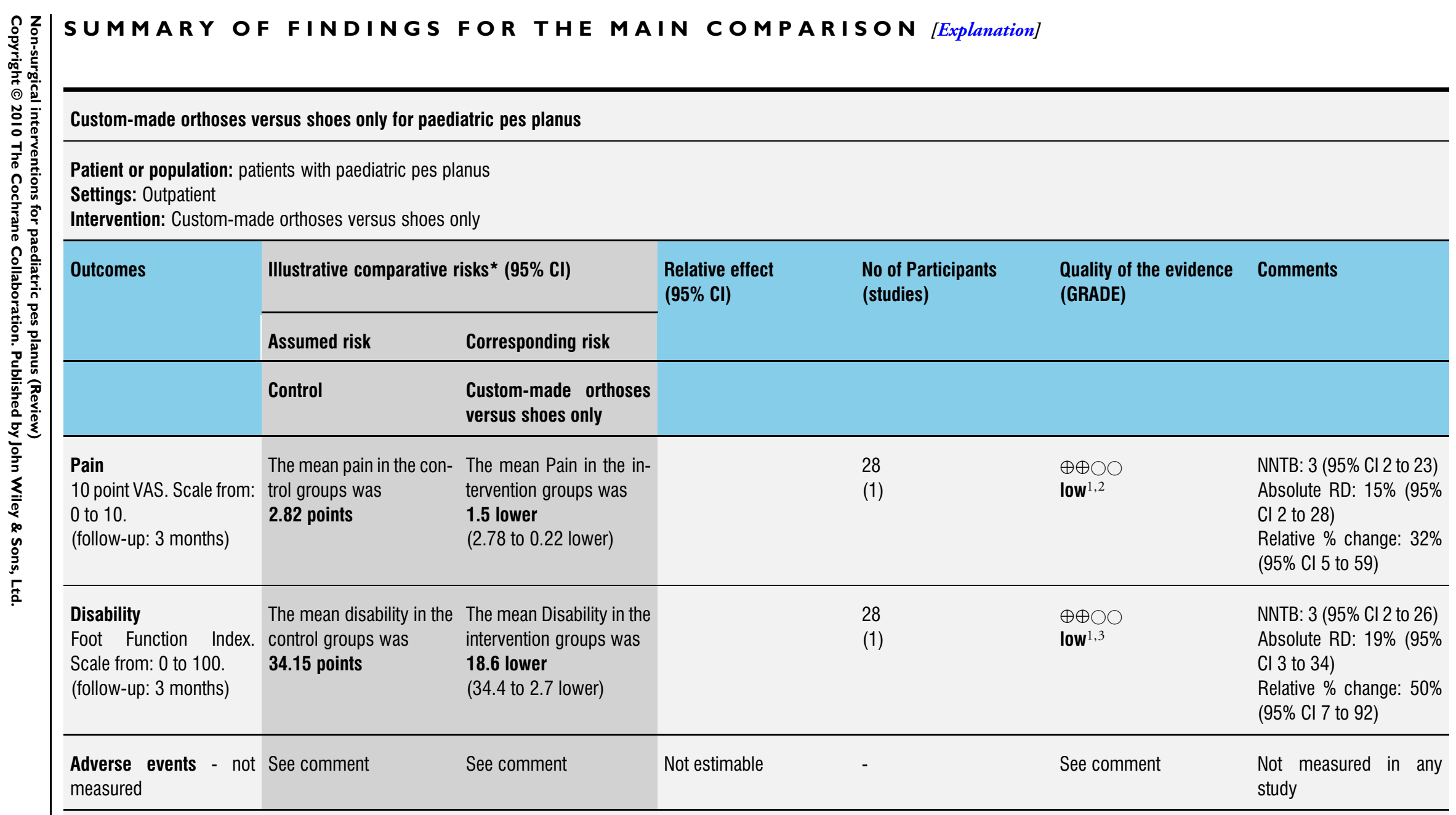

*The basis for the assumed risk (e.g. the median control group risk across studies) is provided in footnotes. The corresponding risk (and its $95 \%$ confidence interval) is based on the assumed risk in the comparison group and the relative effect of the intervention (and its $95 \% \mathrm{Cl}$ ).

Cl: Confidence interval; 
GRADE Working Group grades of evidance

High quality: Further research is very unlikely to change our confidence in the estimate of effect.

Moderate quality: Further research is likely to have an important impact on our confidence in the estimate of effect and may change the estimate.

Low quality: Further research is very likely to have an important impact on our confidence in the estimate of effect and is likely to change the estimate.

Very low quality: We are very uncertain about the estimate.

${ }^{1}$ Data from one small study only, and unclear if allocation concealment was adequate

2 The confidence limit crosses the estimated minimally important difference for the estimated minimally clinically important difference for pain VAS scale ( 0.9 points on 10 point scale)

3 The confidence limit crosses the estimated minimally clinically important difference for the disability subscale of the the Foot Function Instrument (7 points on 100 point scale) 


\section{B A C K G R O U N D}

Pes planus ('flat feet') is one of the most common conditions observed in paediatric health practice (Luhmann 2000; Sullivan 1999). Garcia 1999 reported a prevalence rate of $2.7 \%$ in 1181 children aged between two and 13 years. Pfeiffer 2006 reported that the prevalence of flexible flatfoot in three to six year old children was $44 \%$, but prevalence of pathological flatfoot was less than $1 \%$. As a frequently reported condition it has significant implications. These are not only for the individual, where pain or the appearance of the foot is outside normal expectations, but also for the clinician in terms of treatment and management. Here the challenge is around functionality, where the clinician is requested to align the foot back to within normal foot functioning parameters. There is no universally accepted definition for pes planus. Clinically, a pes planus is a foot that has a low or absent longitudinal arch. A flexible flat foot has an arch that is present in open kinetic chain (non-weight bearing) and lost in closed kinetic chain (weight bearing). A rigid flatfoot has loss of the longitudinal arch height in open and closed kinetic chain (Napolitano 2000). Normally developing infants have a flexible flatfoot and gradually develop a normal arch during the first decade of life (Capello 1998). Luhmann 2000 suggested that the flexible type is a common diagnosis and is one which is usually not problematic and rarely needs treatment. The debate between treating and monitoring asymptomatic and symptomatic pes planus is on-going with no gold standard for treating children with pes planus (Bresnahan 2009; Harris 2010; D’Amico 2009).

There is a wide spectrum of severity and different aetiologies described in the literature for paediatric pes planus (Capello 1998). Staheli 1987 proposed a generic classification of flat foot deformities that differentiated between flat feet due to physiological and pathological aetiologies. Harris 2004 reported that pes planus may exist as an isolated pathology or as part of more widespread clinical pathologies such as generalised ligamentous laxity, neurological and muscular abnormalities, genetic conditions and syndromes, and collagen disorders. Luhmann 2000 stated that tarsal coalitions are the most common cause of rigid flat feet in children and adolescents. Napolitano 2000 postulated that obesity, rotational deformities producing in-toeing or out-toeing, accessory navicular, ankle equinus, and varus and valgus deformities of the tibia, and its relationship to the weight-bearing surface, are risk factors that may play a role in the development and function of the foot.

Not withstanding the underlying pathology of pes planus, there are conflicting opinions on the intervention of paediatric pes planus (Evans 2008; Garcia 1999). The primary goals of treatment of flat feet are relief of pain or disability and the prevention of future disability (Capello 1998). While some experts consider that pes planus is normal in early childhood and that the condition usually resolves spontaneously without treatment (Brooks 1991; Volpon 1994), other experts suggest treatment of the flexible form of pes planus is necessary as it may lead to disability, joint damage and, in later life, a rigid fixed foot deformity (Aharonson 1992; Connors
1998). Luhmann 2000 suggested that the flexible type is a common diagnosis and is one which is usually not problematic and rarely needs treatment. The debate between treating and monitoring asymptomatic pes planus is on-going (D'Amico 2009; Evans 2008; Harris 2010).

The American College of Foot and Ankle Surgeons (Harris 2004) has published clinical practice guidelines for the diagnosis and treatment of paediatric pes planus. Labovitz 2006 conducted a roundtable on the conservative and surgical management of difficult and controversial paediatric cases that included pes planus. An overriding concern is that flatfoot can cause debilitating foot pain in adults and should be diagnosed early and treated appropriately. The controversy about the management of pes planus arises from the contradictory opinions expressed by different authors. Glimore 2002 reported that flexible paediatric pes planus should be observed unless painful, which requires a more extensive evaluation to determine the exact cause. Luhmann 2000 reported that a rigid pes planus is often symptomatic and requires treatment. A flexible pes planus may be either asymptomatic or symptomatic (Sullivan 1999).

The treatment of this condition can vary from conservative management to surgical approaches. The latter are used rarely and generally only after failure of conservative management. A plethora of conservative (non-surgical) interventions has been reported in the literature including advice, foot orthoses (shoe inserts), stretching, footwear selection and modifications, activity modifications, manipulation, serial casting, appropriate weight reduction and antiinflammatory medications. Given the many and varied treatment options, there is a need to identify and evaluate the evidence from randomised trials of non-surgical interventions to inform the management of paediatric pes planus.

\section{O B J E C T I V E S}

The aim of this review was to evaluate the benefits and harms from randomised controlled trials of the non-surgical intervention of paediatric pes planus.

\section{METHODS}

\section{Criteria for considering studies for this review}

\section{Types of studies}

All randomised controlled trials (RCTs) and pseudo-randomised controlled clinical trials (CCTs) (using methods of allocating participants to a treatment which are not strictly random, for example date of birth, hospital record number or alternation) comparing 
non-surgical interventions versus placebo, sham or no intervention (control) or other non-surgical interventions for paediatric pes planus.

\section{Types of participants}

Since there is no universally accepted definition for pes planus, pes planus in this review is the term used to describe a recognizable clinical deformity created by malalignment at several adjacent joints of the foot (Harris 2004). We included trials involving children under 16 years old with a diagnosis or history of pes planus. Studies of various soft tissue diseases and pain due to tendinitis at all sites were eligible for inclusion provided that the pes planus pain results were presented separately. Studies where participants had plantar heel pain, stress fractures of the metatarsals, ankle fractures, rheumatoid foot pathologies, diabetic foot or neuromuscular conditions were also eligible for inclusion, that included children with Juvenile Idiopathic Arthritis, Down's, Marfan or EhlersDanlos syndrome. Juvenile arthritis was included as pes planus is a common clinical feature of the disease (Henry 2008).

\section{Types of interventions}

Interventions included activity modification; manipulation; serial casting; weight reduction; anti-inflammatory medication; rigid, semi-rigid or soft foot orthoses designed to provide support or pain relief; corrective footwear; anti-pronatory strapping; stretching exercises; and educational advice to children or their parents and guardians. We excluded studies involving surgical intervention.

Table 1. Original search strategy

\section{Types of outcome measures}

Primary outcomes

- Pain reduction

- Adverse effects of interventions

Secondary outcomes

- Function or disability indices of the foot

- Goniometric measurements or those that are collated in a gait laboratory that include both kinetic and kinematic data

- Quality of life measures

Of these outcomes, the main outcomes selected for display in the 'Summary of findings' tables are: pain, function or disability, and the proportion of participants experiencing any adverse event.

\section{Search methods for identification of studies}

\section{Electronic searches}

Eligible studies were sought from electronic searches of the Cochrane Central Register of Controlled Trials (CENTRAL) (The Cochrane Library), MEDLINE, EMBASE, CINAHL, Index to Theses, and Dissertation Abstracts. The original MEDLINE search strategy, developed for the protocol, is reported in Table 1. This strategy was used in MEDLINE and adapted to the other databases to capture eligible trials published until October 2007.

\section{MEDLINE}

The following search strategy was the original strategy developed for MEDLINE for this review

1. exp flatfoot/

2. flat foot\$.mp.

3. flatfoot\$.mp.

4. flat feet.mp.

5. flatfeet.mp.

6. pes planus.mp.

7. painful foot.mp.

8. pes planovalgus.mp.

9. posterior tibial tendon dysfunction.mp.

10. subtalar.mp.

11. (sub\$ adj talar).mp.

12. calcane\$.mp.

13. heel bone $\$ . m p$.

14. medical arch $\$ 2 . \mathrm{mp}$.

15. or/1-14

16. exp musculoskeletal diseases/

17. exp neuromuscular diseases/ 
Table 1. Original search strategy (Continued)

18. exp nervous system diseases/

19. ehlers-danlos.mp.

20. down\$ syndrome.mp.

21. trisomy.mp.

22. mongolism.mp.

23. inflammatory arthritis.tw.

24. (juvenile adj3 arthritis).tw.

25. or/ $16-24$

26. exp diabetes mellitus, type $1 /$

27. (diabet $\$$ or IDDM).tw.

28. 26 or 27

29. exp diabetes insipidus/

30. mellitus.tw.

31.29 not $(26$ or 30$)$

32. (diabet\$ adj (insipidus not mellitus)).tw.

33.31 or 32

34. 28 not 33

35. joint instability.sh.

36. ligament\$ laxity.mp.

37. pronat\$.mp.

38. malalignment.mp.

39. or $/ 35-38$

40. or/ $25,34,39$

41. 15 and 40

42. randomized controlled trial.pt.

43. controlled clinical trial.pt.

44. randomized controlled trials.sh.

45. random allocation.sh.

46. double blind method.sh.

47. single-blind method.sh.

48. clinical trial.pt.

49. clinical trials.sh.

50. clinical trial.tw.

51. ((singl\$ or doubl\$ or trebl\$ or tripl\$) and (mask\$ or blind $\$)$ ).tw.

52. placebos.sh.

53. placebo\$.tw.

54. random $\$ . t w$.

55. research design/

56. comparative study.sh.

57. evaluation studies.sh.

58. follow-up studies.sh.

59. prospective studies.sh.

60. control\$.tw.

61. prospectiv\$.tw.

62. volunteer $\$$.tw.

63. or/42-62

64. (animal not human).mp.

65. 63 not 64

66. 41 and 65 
Table 1. Original search strategy (Continued)

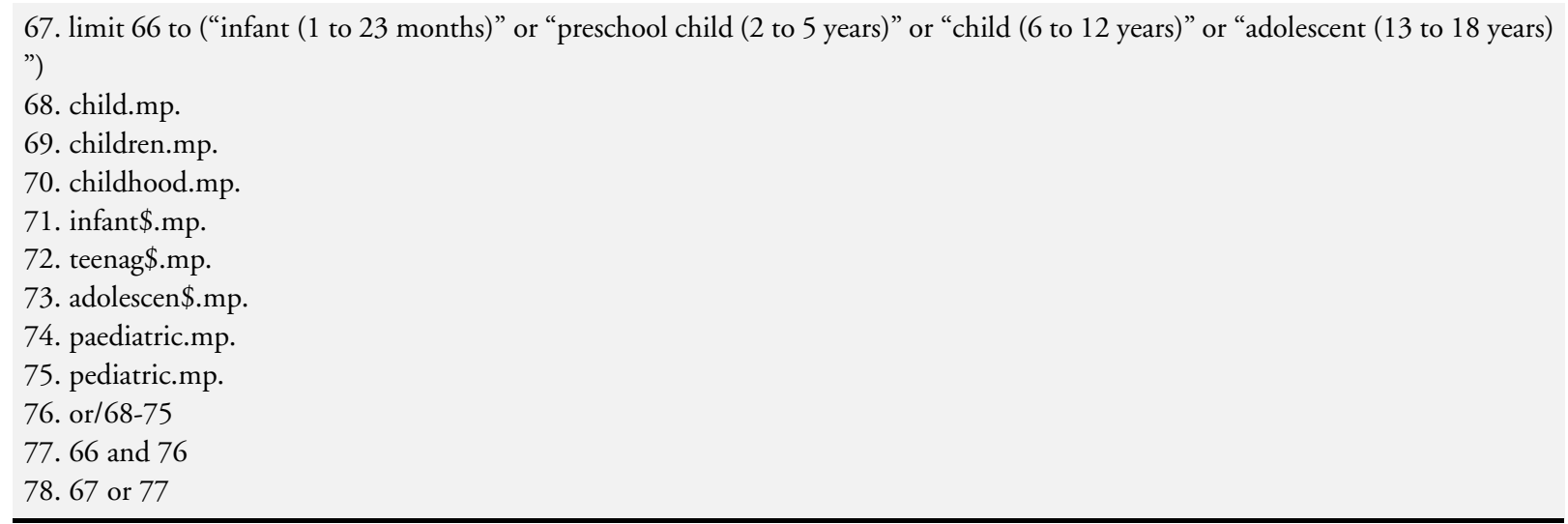

An updated search was conducted (June 2009) to capture eligible publications between 2007 and June 2009 and to incorporate updated recommendations for searching, including an updated optimum search strategy for randomised controlled trials from The Cochrane Collaboration (Lefebvre 2008). The following electronic databases were searched: Cochrane Central Register of Controlled Trials (CENTRAL) (The Cochrane Library 2009, Issue 2), MEDLINE, EMBASE, CINAHL (via EBSCOhost), and Dissertation Abstracts.

In MEDLINE, subject specific search terms and free text words were combined with the optimum search strategy for randomised trials described by Lefebvre 2008 (Appendix 1). The search strategy was adapted for the other databases (Appendix 2; Appendix 3; Appendix 4; Appendix 5).

\section{Searching other resources}

The electronic search was complemented by the following:

- checking reference lists of relevant articles for additional studies reported in published papers, scientific meetings, and personal communications;

- downloads of Current Contents;

- handsearches of abstracts published in special issues of specialised journals or in conference proceedings;

- contact with content experts for additional studies and unpublished data.

\section{Data collection and analysis}

\section{Study identification and selection}

The initial searches were carried out by one of the authors (KR) assisted by the Cochrane Musculoskeletal Group's Search Specialist at the editorial base. Pairs of review authors (KR and AE; KR and RA) assessed potentially eligible trials for inclusion and any disagreement was resolved through discussion. Titles of journals and names of authors or supporting institutions were not masked at any stage. The authors will update the review on a two year cycle.

\section{Assessment of risk of bias of included studies}

Two review authors independently assessed the risk of bias of each included trial against key criteria: random sequence generation; allocation concealment; blinding of participants, personnel and outcomes; incomplete outcome data; selective outcome reporting; and other sources of bias. This is in accordance with methods recommended by The Cochrane Collaboration (Higgins 2008). Each of these criteria were explicitly judged using: Yes (low risk of bias); No (high risk of bias); or Unclear (either lack of information or uncertainty over the potential for bias). Review authors resolved disagreements by consensus.

\section{Data extraction}

All three authors independently performed data extraction, two using a pre-piloted form. Any disagreement was resolved through discussion. This procedure was undertaken by electronic communications between the review authors.

\section{Data analysis}

For each study, we calculated mean differences (MD) and 95\% confidence intervals (CI) for continuous outcomes. We planned to conduct meta-analyses; however we found insufficient data for meta-analysis. 


\section{Summary of findings tables}

The main results of the review (pain reduction, function or disability, and number of patients experiencing any intervention-specific adverse event) were presented for the comparison custommade foot orthoses versus control (shoe only) in a 'Summary of findings' table, which provides key information concerning the quality of evidence, the magnitude of effect of the interventions examined and the sum of available data on the main outcomes, as recommended by The Cochrane Collaboration (Schünemann 2008a). In addition to the absolute and relative magnitude of effect provided in the 'Summary of findings' table, the number needed to treat to benefit (NNTB) and number needed to treat to harm (NNTH) were calculated for each statistically significant estimate of effect, for any outcome. For dichotomous outcomes, NNT was to be calculated from the control group event rate and the relative risk using the Visual Rx NNT calculator (Cates 2004); however, relevant dichotomous outcomes were not reported in the included trials. For continuous outcomes (for example reduction in pain), the NNTB was calculated using the Wells calculator software available at the Cochrane Musculoskeletal Group (CMSG) editorial office (http://www.cochranemsk.org/). The minimal clinically important differences (MCID) are used in the calculator: we assumed a MCID of 0.9 points for pain measured by a 10-point visual analogue scale (VAS) and 7 points for disability measured by the 100 point Disability subscale of the Foot Function Index, as calculated by Landorf 2008. Absolute change (benefit) was calculated from the mean difference and expressed as a percent and in the original units, and relative difference in the change from baseline was calculated as the absolute benefit divided by the baseline mean of the control group. The 'Summary of findings' table includes an overall grading of the evidence related to each of the main outcomes, using the GRADE approach (Schünemann 2008b).

\section{RE S U L T S}

\section{Description of studies}

See: Characteristics of included studies; Characteristics of excluded studies.

Fifteen studies were originally identified for this review, with only three studies meeting the eligibility criteria (Powell 2005; Whitford 2007; Wenger 1989). One RCT was excluded as the intervention related to juvenile hallux valgus (Kilmartin 1994). Another RCT was excluded as the intervention specifically relating to metatarsus primus varus (Camin 2004). The 10 other studies (Bahler 1986; Battaglia 1988; Bleck 1977; Bordelon 1980; Capasso 1993; Gould 1989; Jay 1995; Mereday 1972; Niedzielski 1993; Redmond 2000) were excluded because they were non-randomised clinical trials. Additional information details of each of these excluded studies are reported in the 'Characteristics of excluded studies' table.

The three studies that were included were conducted in two countries (USA and Australia) and published in English.

One study evaluated 40 children, aged 5 to19 years, with diagnosed juvenile chronic arthritis with pes planus with pain (Powell 2005). The primary outcome measure was pain reduction using a Paediatric Pain questionnaire, measured on a $100 \mathrm{~mm}$ VAS. Secondary outcome measures included the Physical Functioning subscale of the Paediatric Quality of Life Inventory (Varni 2002). Foot function was assessed using the Foot Function Index (Budiman 1991). The Foot Function Index was developed to measure the impact of foot pathology on function in terms of pain, disability and activity restriction. A 50-foot timed walk was also evaluated. Each child was randomised into one of three intervention groups: (1) custom-made semi-rigid orthotics made of metal-particle reinforced plastic with shock-absorbing posts; (2) prefabricated shoe inserts made from flat neoprene; and (3) new supportive athletic shoes with a medial longitudinal arch and shock-absorbing insoles. All children received new athletic shoes at the beginning of the study.

Wenger 1989 evaluated 129 children, aged 1 to 6 years, with clinically diagnosed pes planus and no pain. Bilateral pes planus was diagnosed by visual observation of the valgus position of the heel and the low appearance of the arch upon weight bearing. Outcome measures included anterior-posterior radiographs and goniometric measurements of ankle joint dorsiflexion, an assessment for muscle tightness of the primary ankle plantarflexion muscles and joint laxity. Each child was randomised into one of four groups: (1) orthopaedic shoes with no corrective features, the shoes were normal in contour and contained a steel shank; (2) shoes with a Thomas heel, a long medial counter and a navicular pad; (3) shoes with a Thomas heel, a long medial counter and a heel cup; (4) shoes that had a University of California Biomechanics Laboratory (UCBL) custom-made plastic insert.

Whitford 2007 evaluated 178 children, aged 7 to 11 years, with clinically diagnosed pes planus and no pain. Bilateral pes planus was diagnosed by the assessment of calcaneal eversion in the relaxed calcaneal stance position and by the navicular drop test. The navicular drop test measures the extent of excessive foot pronation. The primary outcomes measures included a motor proficiency test using the Bruininks Oseretsky Test (Reeves 1999). This test consists of four subscales: running speed and agility, balance, bilateral co-ordination, and strength. Pain was assessed on a VAS for current pain using the Child Form of the Varni Thompson Paediatric Pain questionnaire (Varni 1996). Self-perception was also measured using the 'Self-perception profile for children' (van den Bergh 2003). Other variables measured included body mass index, ligamentous laxity and evaluation of ankle joint plantar flexors. Ligamentous laxity was measured using a joint hypermobility scale (Gedalia 1993) and ankle joint dorsiflexion was measured with the knee both extended and flexed. Each child was randomised into one of 
three groups: (1) custom-made foot orthoses made from a rigid thermoplastic material with a vinyl cover; (2) prefabricated foot orthoses made from a semi-rigid thermoplastic material with a standard intrinsic heel postings of $4^{\circ}$ and a $5 \mathrm{~mm}$ metatarsal rise; (3) no treatment. All children with shortened ankle joint plantar flexors were taught how to conduct calf muscle stretches at home and the researchers discussed suitable shoes with the parents.

Defintions of pre-fabricated and custom-made foot orthoses are in Table 2.

Table 2. Glossary of terms used to describe foot orthoses

\begin{abstract}
Pre-fabricated foot orthoses definition:
A pre-made foot orthoses is an in-shoe medical device that is not made from a custom mould of the plantar foot and which is intended to alter the magnitudes and temporal patterns of the reaction forces acting on the plantar aspect of the foot in order to allow more normal foot and lower extremity function and to decrease pathologic loading forces on the structural components of the foot and lower extremity during weight-bearing activities.
\end{abstract}

Custom-made foot orthoses definition: A prescription foot orthoses is a custom fit in-shoe medical device that is made from a custom mould of the plantar foot, prescribed by a qualified health-care professional and which is designed by that professional to alter the magnitudes and temporal patterns of the reaction forces acting on the plantar aspect of the foot in order to allow more normal foot and lower extremity function and to decrease pathologic loading forces on the structural components of the foot and lower extremity during weight-bearing activities.

\section{Risk of bias in included studies}

All three trials reported that participants were randomised to an intervention, but only one trial adequately described the method used to generate the random sequence (Whitford 2007). Wenger 1989 and Whitford 2007 did not describe if allocation of treatment was concealed. Powell 2005 attempted to conceal allocation but did not report the method used in enough detail for us to judge if concealment was adequate.

All three trials reported on the reasons patients withdrew from the study. Two studies were unlikely to have biased results due to participant withdrawals (Powell 2005; Whitford 2007). It is unclear if the exclusion of 25 non-compliant participants from Wenger 1989 biased the results of the study as the trial authors did not report which treatment groups these participants were from. We were unable to compare baseline characteristics such as age. In all studies the outcome assessors were clearly blinded to participant status. Due to the nature of the interventions the criterion 'patient blinded' could not be achieved. In the three studies, treatment and control groups were likely similar at baseline, based on the shared characteristics of the study population, for example children who met the variable criteria of flexible flatfeet.

Care programmes other than the trial options were the same in all treatment groups. Powell 2005 issued athletic shoes to all children, whereas Whitford 2007 gave advice to all parents about suitable shoes. Wenger 1989 provided a pedorthotist for all follow-up visits to ensure that all the corrective shoes were fitted according to the standards and specifications of the Prescription Footwear Association. Whitford 2007 also prescribed calf muscle stretches to children who required stretching. The inclusion and exclusion criteria used in all studies were clearly defined.

The primary outcome measure of pain reduction was reported in Powell 2005; measured, but not reported in a form that could be extracted into meta-analysis in Whitford 2007; and not reported in Wenger 1989. Whitford 2007 measured pain using a continuous outcome measure (VAS scale) but reported the proportions of participants with or without pain at follow up. Wenger 1989 stated that parents reported a reduction in pain symptoms in children with flat feet across the four groups (corrective shoes, heel cup, UCBL insert and the control group) but no data were provided. However, secondary outcome measures were not clearly defined in the trials. Follow up was varied in all three studies. Two trials were conducted over 12 weeks (Powell 2005; Whitford 2007); Wenger 1989 was conducted over 36 weeks.

\section{Effects of interventions}

See: Summary of findings for the main comparison

Due to the limited number of trials and the differences in the interventions and outcomes reported, data were not pooled. A total of 305 children, ranging from 1 to 19 years old, were included 
in the review.

\section{Custom-made orthoses versus shoes}

\section{Pain}

Data could be extracted from one study only for this outcome. Powell 2005 found a significantly greater reduction in pain with the custom-made orthoses over three months compared to that achieved with the shoes only (MD -1.5 points, $95 \%$ CI -2.8 to $0.2,10$-point VAS scale) (Analysis 1.1). All other results were nonsignificant.

\section{Adverse effects}

No adverse events were reported in any trial.

\section{Secondary outcomes}

\section{Function or disability indices of the foot}

Powell 2005 investigated the Activity Limitation subscale of the Foot Function Index (Budiman 1991) and demonstrated significant improvement with custom-made orthoses compared with shoes only, after three months (MD - 19 points, $95 \%$ CI -35 to 3, 0 to 100 scale) (Table 3). In addition, the Disability subscale of the Foot Function Index (Budiman 1991) demonstrated significant improvement with custom-made orthoses compared with shoes after three months (MD -19 points, $95 \%$ CI -34 to $-3,0$ to 100 scale) (Table 3). Functional or disability indices of the foot were not measured in Wenger 1989.

Table 3. Custom-made orthoses versus shoes on secondary outcomes after 3 months

\begin{tabular}{l|lllll}
\hline Outcome measures & No. of participants & Custom-made FOs & Shoes & Statistical method & Effect size \\
\hline $\begin{array}{l}\text { Foot Function In- } \\
\text { dex - activity limita- } \\
\text { tion }\end{array}$ & 28 & $8.54(11.06)$ & $27.92(27.89)$ & MD, 95\%CI & $-19.38(-35.54,-3.22)$ \\
\hline $\begin{array}{l}\text { Foot Function In- } \\
\text { dex - disability }\end{array}$ & 28 & $15.60(13.51)$ & $34.15(26.35)$ & MD, 95\%CI & $-18.65(-34.42,-2.68)$ \\
\hline PedsQL - child & 25 & $71.88(15.88)$ & $55.95(13.97)$ & MD, 95\%CI & $9.01(-4.08,22.10)$ \\
\hline PedsQL - parent & 25 & $64.96(19.92)$ & $55.05(13.97)$ & MD, 95\%CI & $-0.64(-2.05,13.28)$ \\
\hline
\end{tabular}

\section{Health-related quality of life}

One trial (Powell 2005) investigated the effect of an intervention on the health-related quality of life using the self-reported Physical Functioning subscale of the Paediatric Quality of Life inventory (Varni 2002) but found no significant differences between treatment groups (Table 3). Health-related quality of life was not measured in Wenger 1989.

Goniometric measurement of ankle joint range of motion Goniometric measurement of ankle plantar flexors was reported in Wenger 1989 but no data were available to be extracted into this review. In a trial of 98 children, calf muscle tightness was recorded but no data were available (Wenger 1989).

\section{Custom-made orthoses versus prefabricated orthoses}

\section{Primary outcomes}

Pain

Data could only be extracted from Powell 2005, who reported no significant differences in pain scores between the two treatment groups at 3 months follow up (MD - 1.5 points, $95 \%$ CI -3.3 to 0.2 , 10-point VAS scale) (Analysis 2.1). The data from Whitford 2007 were not calculated as the results were measured using a continuous VAS scale but presented as the proportion of participants with and without pain. Wenger 1989 did not measure pain reduction in their study.

\section{Adverse effects}


No adverse events were reported in any trial.

\section{Secondary outcomes}

\section{Function or disability indices of the foot}

Data from one study (Powell 2005) investigating the Activity Limitation subscale and the Disability subscale of the Foot Function Index (Budiman 1991) demonstrated no significant differences between treatment groups, at three months (Table 4). Functional or disability indices of the foot were not measured in the other trials (Wenger 1989; Whitford 2007).

Table 4. Custom-made versus prefabricated orthoses on secondary outcomes at 3 months

\begin{tabular}{|c|c|c|c|c|c|}
\hline Outcome Measure & No of participants & Custom-made FOs & Prefabricated FOs & Statistical Method & Effect Size \\
\hline $\begin{array}{l}\text { Foot Function In- } \\
\text { dex - activity limita- } \\
\text { tion }\end{array}$ & 28 & $8.54(11.06)$ & $19.96(19.73)$ & MD 95\%CI & $11.42(-23.91,1.07)$ \\
\hline $\begin{array}{l}\text { Foot Function In- } \\
\text { dex - disability }\end{array}$ & 28 & $15.60(13.51)$ & $29.98(25.26)$ & MD 95\%CI & $\begin{array}{l}-14.38 \quad(-30.22, \\
1.46)\end{array}$ \\
\hline PedsQL - child & 23 & $71.88(15.88)$ & $55.94(17.46)$ & MD 95\%CI & $15.94(2.10,29.78)$ \\
\hline PedsQL - parent & 24 & $64.96(19.92)$ & $55.31(15.80$ & MD 95\%CI & $9.65(-4.66,23.96)$ \\
\hline
\end{tabular}

\section{Health-related quality of life}

One trial (Powell 2005) investigated the effect of an intervention on the health-related quality of life in 40 participants with foot pain. Over the three-month trial period, a significant improvement in physical functioning was found on the child self-reported Physical Functioning subscale of the Paediatric Quality of Life inventory (Varni 2002) with prefabricated shoe inserts compared to custom-foot orthoses (MD 16 points, 95\% CI 2 to 30, 0 to 100 scale) (Table 4). Health-related quality of life measures were not used in the other trials (Wenger 1989; Whitford 2007).

\section{Goniometric measurement of ankle joint range of motion}

Goniometric measurement of ankle plantar flexors was reported in two studies (Wenger 1989; Whitford 2007) but no data were available to be extracted into this review. In one trial of 178 children, only baseline measurements were reported for each trial group (Whitford 2007). In another trial of 98 children, calf muscle tightness was recorded but no data were available (Wenger 1989).

\section{Prefabricated orthoses versus shoes}

\section{Primary outcomes}

\section{Pain}

Data from one included trial (Powell 2005) inidcated no significant differences in pain scores between the two treatment groups at three-months follow up (MD 0.0, 95\% CI 1.9 to 2.0) (Analysis 3.1).

\section{Adverse effects}

No adverse events were reported in any trial.

\section{Secondary outcomes}

Function or disability indices of the foot 
Data from one trial (Powell 2005) that measured disability using the Foot Function Index (Budiman 1991) demonstrated no significant difference in the Activity Limitation subscale between treatment groups, after three months (Table 5); and no significant difference between treatment groups in the Disability subscale at three months (Table 5).

Table 5. Prefabricated orthoses versus shoes on secondary outcome measures at 3 months

\begin{tabular}{|c|c|c|c|c|c|}
\hline Outcome measures & No. of participants & Prefabricated FOs & Shoes & Statistical Method & Effect size \\
\hline $\begin{array}{l}\text { Foot Function In- } \\
\text { dex - activity limita- } \\
\text { tion }\end{array}$ & 25 & $19.96(19.73)$ & $27.92(27.89)$ & MD 95\%CI & $-7.96(-26.79,10.87)$ \\
\hline $\begin{array}{l}\text { Foot Function In- } \\
\text { dex - disability }\end{array}$ & 25 & $29.98(25.26)$ & $34.15(26.35)$ & MD 95\%CI & $-4.17(-24.40,16.06)$ \\
\hline PedsQL - child & 22 & $55.94(17.46)$ & $59.78(18.80)$ & MD 95\%CI & $-3.84(-19.01,11.33)$ \\
\hline PedsQL - parent & 22 & $55.31(15.80)$ & 55.95 (13.97) & MD 95\%CI & $-0.64(-13.22,11.94)$ \\
\hline
\end{tabular}

\section{Health-related quality of life}

One trial (Powell 2005) investigated the effect of an intervention on the health-related quality of life in 22 participants with foot pain, using the Paediatric Quality of Life Inventory (Varni 2002). They demonstrated no significant difference between groups, child or parent, on the Physical Functioning subscale of the Inventory (Table 5).

\section{Goniometric measurement of ankle joint range of motion}

Goniometric measurement of ankle plantar flexors was reported in Wenger 1989 but no data were available to be extracted into this review. In another trial of 98 children, calf muscle tightness was recorded but no data were available (Wenger 1989).

\section{DISCUSSION}

There is a lack of good quality studies that have evaluated nonsurgical interventions for paediatric pes planus. Evidence from a single trial indicates that custom-made foot orthoses may improve pain and disability in children with juvenile chronic arthritis and pes planus (Powell 2005), Summary of findings for the main comparison, but the clinical importance of the improvements are questionable, and further studies are likely to change the conclusions. There was clinical and methodological heterogeneity across studies that precluded meta-analysis and robust overall conclusions. Furthermore, the small number of relevant trials and limited sample sizes precludes firm conclusions regarding any one intervention. Sources of heterogeneity include the age ranges studied, co-morbidities, interventions, and outcome measures chosen.

\section{Methodological issues}

The sample size of the treatment trials ranged from 40 to 164 , with two trials having less than 100 participants. With such small sample sizes it is not possible to draw robust conclusions. This is primarily due to a number of factors including limited number of studies per interventions compared combined with the small sample sizes of the studies. Therefore, as a consequence of data heterogeneity no meta-analysis could be meaningfully conducted. The three studies were single-blind trials with the investigators being aware of the type of intervention received, which may have resulted in performance and detection (assessor) bias. Blinded healthcare providers may also differ from non-blinded ones in their degree of attention to patients, or in their use of alternative forms of care. Time frames varied across the three trials, ranging from three to 36 weeks, therefore making comparisons difficult.

The age ranges differed across the three studies and it is therefore difficult to generalise about non-surgical intervention for paediatric pes planus in children. For example, one studied five to 19 year olds, one studied seven to 11 year olds, and the other studied one to six year olds. One of the studies included children with juvenile chronic arthritis (Powell 2005) while the other two studies 
included otherwise healthy children with flat feet (Wenger 1989; Whitford 2007).

The current review demonstrated a limited range of non-surgical interventions for paediatric pes planus. The only studies eligible for inclusion in this systematic review utilised foot orthoses and shoes. The range of foot orthoses reported on included prefabricated, custom-made othoses and heel cups specifically designed for paediatric pes planus (Wenger 1989). There was limited technical information about the manufacturing process, construction and prescription of the foot orthoses. The type of shoes included orthopaedic shoes (Wenger 1989), new supportive athletic shoes (Powell 2005), and a child's own shoes worn at the time of the study (Whitford 2007).

Only one trial reported on adverse effects and the authors reported no adverse effects with the use of foot orthoses and shoes (Powell 2005). However, with only one trial reporting on this variable, and given the limitations of the data available, a degree of caution must be noted. No trial reported patient comfort. Landorf 2007 wrote that orthotic comfort may be an important variable and may explain the efficacy (or perceived efficacy) of foot orthoses for any intervention programme. Future research may consider evaluating self-reported comfort.

Previous systematic reviews have reported on the efficacy of foot orthoses by performing either kinematic or kinetic gait analysis, or both (Burns 2007; Hawke 2008; Hawke 2009). In the current review only hand-held goniometry was performed, in two studies, and data were not available to conduct any analysis (Wenger 1989; Whitford 2007).

\section{Outcome measures}

A number of outcome measures were reported in the three trials. Two studies (Powell 2005; Whitford 2007) investigated the primary outcome specified by this review (pain reduction) but over three months and 12 months, respectively. It is unclear if the Varni Thompson Paediatric Pain questionnaire (Varni 2002) used by Whitford 2007 related to symptoms in the children's feet and lower extremities only, or if whole body pain was included. One trial conducted a subgroup analysis of pain reduction for those children who reported lower-limb pain at baseline (Whitford 2007). However, the study design did not have an a priori hypothesis to specifically test the effects of functional foot orthoses on the treatment of painful pes planus.

The three trials (Powell 2005; Wenger 1989; Whitford 2007) did not use the same secondary outcome measures, which made it difficult to combine the results. A number of secondary outcome measures in the three trials were generic outcome measures not specific to the foot and may not be specific to symptomatic flatfoot. Radiographic evaluation was reported in one study but it was not nominated as an outcome in this review (Wenger 1989).

\section{A U THORS' CONCLUSIONS}

\section{Implications for practice}

Evidence from one randomised controlled trial investigating children with chronic juvenile arthritis suggests that custom-made foot orthoses may be effective in reducing pain compared with compared with prefabricated and newly supportive athletic shoes after three months. Based on the results of this review we also conclude that there is no evidence from randomised controlled trials on the efficacy of foot orthoses for asymptomatic paediatric pes planus. Furthermore, there is no evidence from randomised trials for any other non-surgical intervention. Intervention with foot orthoses has few side effects, but the optimal choice of orthoses remains unclear and long-term implications are lacking.

\section{Implications for research}

Pes planus is a common musculoskeletal condition that often presents itself in clinical practice. The methodological quality of studies investigating the effectiveness of non-surgical interventions has to be improved. From a methodological perspective, one general foot score would allow pooling of the results.

Future studies should focus on the most clinically relevant outcomes, which may include pain reduction and indices that evaluate function and disability. It is only through the use of similar outcome measures that studies can be combined and hence we will be able to obtain pooled estimates. We can then obtain some consensus on the varied non-surgical intervention options.

Further trials are required examining both the short-term and long-term benefits of non-surgical interventions such as foot orthoses or footwear. Future trials are required, with more participants, to evaluate if the differences are real and clinically worthwhile. Short-term benefit needs to be established first in order to justify the considerable resources required, as well as the ethical implications involved, for a lengthy study in this area. Subsequently, a follow-up period of at least five years is needed because of the bony changes within the lower limb and foot in children of this age to observe if pes planus in children predispose to problems in adults. If there no differences are observed then there would be no need to treat asymptomatic pes planus.

Further studies are required to evaluate intervention comparisons, that is interventions need to be evaluated against standard conservative care. If feasible, foot orthoses should be compared with other modalities such as shoe designs, muscle stretching and strengthening, strapping and joint range of motion exercises. Future studies should also report on the technical information of the foot orthoses, commencing with the manufacturing process and extending to the materials used in the construction of foot orthoses. 


\section{ACKNOWLEDGEMENTS}

The authors would like to thank Helen Handoll, University of Teesside, UK for help with preparation of this protocol; Julie Hogg, University of Teesside, UK for the assistance in developing the original search strategy; and Louise Falzon, Trial Search Coordinator, Cochrane Musculoskeletal Group, for updating the search strategy and running the updated searches. We would like to thank the following people for translating articles into English: Miranda Cumpston, formerly of the Cochrane Musculoskeletal Group; Gustavo Zanoli, Cochrane Musculoskeletal Group; Anette Bluemle, German Cochrane Centre; Lorenzo Moja, Italian Cochrane Centre; and Malgorzata Bala, Department of Internal Medicine, Jaiellonian University Medical College, Krakow, Poland.

\section{REFERENCES}

\section{References to studies included in this review}

Powell 2005 \{published data only\}

Powell M, Seid M, Szer IS. Efficacy of custom foot orthotics in improving pain and functional status in children with juvenile idiopathic arthritis: a randomised trial. Journal of Rheumatology 2005;32:943-50

Wenger 1989 \{published data only\}

Wenger DR, Mauldin D, Spleck G, Morgan D, Lieber RL. Corrective shoes and inserts as treatment for flexible flatfoot in infants and children. The Journal of Bone and Joint Surgery 1989; 71-A:800-10.

Whitford 2007 \{published data only\}

Whitford D, Esterman A. A randomised controlled trial of two types of in-shoe orthoses in children with flexible excess pronation of the feet. Foot \& Ankle International 2007;28:715-23.

\section{References to studies excluded from this review}

Bahler 1986 \{published data only\}

Bahler A. Provision of insoles for flexible flatfeet in children. Der Orthopade 1986;15:205-11.

Battaglia 1988 \{published data only\}

Battaglia A, Majotti M, Ingravalle R. Orthotic treatment in flexible pes valgus. Chirgurgia del Piede 1988;12:105-8.

Bleck 1977 \{published data only\}

Bleck EE, Berzins UJ. Conservative management of pes valgus with plantar flexed talus, flexible. Clinical Orthopaedics and Related Research 1977;122:85-94.

Bordelon 1980 \{published data only\} Bordelon RL. Correction of hypermobile flatfoot in children by molded insert. Foot \& Ankle International 1980;1:143-50.

Camin 2004 \{published data only\}

Camin M, Vangelista A, Cosentino A, Fiaschi A, Smania N. Early and delayed orthotic treatment in congenital metatatarsus varus: effectivness of two types of orthoses. Europa Medicophysica 2004; 40:285-91.
Capasso 1993 \{published data only\}

Capasso G. Dynamic varus heel cup: a new orthosis for treating pes planovalgus. Italian Journal of Orthopaedic Traumatology 1993;19: 113-23.

Gould 1989 \{published data only\}

Gould N, Moreland M, Alvarez R, Trevino S, Fenwick J.

Development of the child's arch. Foot \& Ankle International 1989; 9:241-5.

Jay 1995 \{published data only\}

Jay RM, Schoenhaus HD, Seymour C, Gamble S. The Dynamic Stabilising Innersole System (DSIS): The management of hyperpronation in children. Journal of the American Podiatric Medical Association 1995;34:124-31.

Kilmartin 1994 \{published data only\}

Kilmartin TE, Barrington RL, Wallace WA. A controlled prospective trial of a foot orthoses for juvenil hallux valgus. The Journal of Bone and Joint Surgery. British volume 1994;76-B:210-4.

Mereday 1972 \{published data only\}

Mereday C, Dolan CM, Lusskin R. Evaluation of the University of Calfornia Biomechanics Laboratory shoe insert in 'flexible' pes planus. Clinical Orthopaedics and Related Research 1972;82:45-58.

Niedzielski 1993 \{published data only\}

Niedzielski K, Zwierzchowski H. An influence of therapeutic exercises and hindfoot supinating shoe insert on flatfoot in children. Chirurgia Narzadow Ruchu i Orthopedia Polska 1993;58:46-51.

Redmond 2000 \{published data only\}

Redmond A. The effectiveness of gait plates in controlling in-toeing symptoms in young children. Journal of theAmerican Podiatric Medical Association 2000;90:70-6.

\section{Additional references}

\section{Aharonson 1992}

Aharonson Z, Arcan M, Steinback TV. Foot-ground pressure pattern of flexible flatfoot in childrenm with and without correction of calcaneovalgus. Clinical Orthopaedics and Related Research 1992; 181:177-82. 


\section{Bresnahan 2009}

Bresnahan P. The flat-footed child-to treat or not to treat what is the clinician to do?. Journal of American Podiatric Medical Association 2009;99:178.

\section{Brooks 1991}

Brooks MH. Flatfeet in children. BMJ 1991;302:237.

\section{Budiman 1991}

Budiman-Mak E, Conrad KJ, Roach K. The Foot Function Index: A measure of foot pain and disability. Journal of Clinical Epidemiology 1991;44:561-70.

\section{Burns 2007}

Burns J, Landorf KB, Ryan MM, Crosbie J, Ouvrier RA. Interventions for the prevention and treatment of pes cavus. Cochrane Database of Systematic Reviews 2007, Issue 4. [Art. No.: CD006154. DOI: 10.1002/14651858.CD006154.pub2]

\section{Capello 1998}

Cappello T, Song KM. Determining treatment of flatfeet in children. Current Opinion in Pediatrics 1998;10:77-81.

\section{Cates 2004}

Cates C. Visual Rx 2.0 NNT Calculator [Computer program]. Dr Chris Cates EBM Website. www.nntonline.net 2004.

\section{Connors 1998}

Connors JF, Wernick E, Lowy LJ, Falcone J, Volpe RG. Guidelines for evaluation and management of five common podopediatric conditions. Journal of the American Podiatric Medical Association 1998;88:206-22.

\section{D'Amico 2009}

D'Amico JC. The flat-footed child-to treat or not to treat: what is the clinician to do?. Journal of American Podiatric Medical Association. 2009;99:267-8.

\section{Evans 2008}

Evans AM. The flat-footed child-to treat or not to treat: What Is the clinician to do?. Journal of the American Podiatric Medical Association 2008;98:386-93.

\section{Garcia 1999}

Garcia-Rodriguez A, Martib-Jimenez F, Carnero-Varo M, GomezGarcia E, Gomez-Aracena J, Fernanedz-Crehuet J. Flexible flat feet in children: a real problem?. Pediatrics 1999;103:84-6.

Gedalia 1993

Gedalia A, Brewer EJ. Joint hypermobility in paediatric practice - a review. The Journal of Rheumatology 1993;20:371-4.

\section{Glimore 2002}

Gilmore A, Thompson GH. Common childhood foot deformities: to treat, to wait, or to refer?. Journal of Musculoskeletal Medicine 2002;19:287-95.

\section{Harris 2004}

Harris EJ, Vanore JV, Thomas JL, Kravitz SR Mendelson SA, Mendicino RW, et al.Diagnosis and treatment of pediatric flatfoot. The Journal of Foot and Ankle Surgery 2004;43:341-73.

Harris 2010

Harris EJ. The natural history and pathophysiology of flexible flatfoot.. Clinic in Podiatric Medicine \& Surgery. 2010;27:1-23.

\section{Hawke 2009}

Hawke F, Burns J. Understanding the nature and mechanism of foot pain. The Journal of Foot and Ankle Research 2009;14:21.

\section{Hawke 2008}

Hawke F, Burns J, Radford JA, du Toit V. Custom-made foot orthoses for the treatment of foot pain. Cochrane Database of Systematic Reviews 2008, Issue 3. [Art. No.: CD006801. DOI: 10.1002/14651858.CD006801.pub2]

\section{Henry 2008}

Hendry G, Gardner-Medwin J, Watt GF, Woodburn J. . A survey of foot problems in juvenile idiopathic arthritis.. Musculoskeletal Care. 2008;6:221-232..

\section{Higgins 2008}

Higgins JPT, Altman DG (editors). Chapter 8: Assessing risk of bias in included studies. In: Higgins JPT, Green S (editors). Cochrane Handbook for Systematic Reviews of Interventions Version 5.0.1 (updated September 2008). The Cochrane Collaboration, 2008. Available from www.cochrane-handbook.org.

\section{Labovitz 2006}

Labovitz JM, Bernard MA, Harris EJ, Schoenhaus HD. Difficult and controversial pediatric cases: a roundtable on conservative and surgical management. Clinics in Podiatric Medicine and Surgery 2006;23:77-118.

\section{Landorf 2007}

Landorf KB, Keenan AM. Do foot orthoses prevent injury?. McCauley D \& Best T (Editors), Evidence-based Sports Medicine (2nd edition). Blackwell Publishing: Massachusetts, 2007.

\section{Landorf 2008}

Landorf KB, Radford JA. Minimal important difference: Values for the foot health status questionnaire, foot function index and visual analogue scale. The Journal of Foot and Ankle Surgery 2008;18(1): 15-9. [DOI: doi:10.1016/j.foot.2007.06.006]

\section{Lefebvre 2008}

Lefebvre C, Manheimer E, Glanville J. Chapter 6: Searching for studies. In: Higgins JPT, Green S (editors). Cochrane Handbook for Systematic Reviews of Interventions Version 5.0.1 (updated September 2008). The Cochrane Collaboration, 2008. Available from www.cochrane-handbook.org.

\section{Luhmann 2000}

Luhmann SJ, Rich MM, Schoenecker PL. Painful idiopathic rigid flatfoot in children and adolescents. Foot \& Ankle International 2000;21:59-66.

\section{Napolitano 2000}

Napolitano C, Walsh S, Mahoney L, McCrea J. Risk factors that adversely modify the natural history of the pediatric pronated foot. Clinics in Podiatric Medicine and Surgery 2000;17:397-417.

\section{Pfeiffer 2006}

Pfeiffer M, Kotz R, Ledl T, Hauser G, Sluga M. Prevalence of flatfoot in preschool-aged children. Pediatrics 2006;118:634-9.

\section{Reeves 1999}

Reeves L, Broeder CE, Kennedy-Honeycutt L, East C, Matney L. Relationship of fitness and gross-motor skills for five to six year olds. Perception and Motor Skills 1999;89:739-47.

\section{Schünemann 2008a}

Schünemann HJ, Oxman AD, Higgins JPT, Vist GE, Glasziou P, Guyatt GH. Chapter 11: Presenting results and 'Summary of findings tables'. In: Higgins JPT, Green S (editors). Cochrane 
Handbook for Systematic Reviews of Interventions Version 5.0.1 (updated September 2008). The Cochrane Collaboration, 2008. Available from www.cochrane-handbook.org.

\section{Schünemann 2008b}

Schünemann HJ, Oxman AD, Vist GE, Higgins JPT, Deeks JJ, Glasziou P, Guyatt GH. Chapter 12: Interpreting results and drawing conclusions. In: Higgins JPT, Green S (editors). Cochrane Handbook for Systematic Reviews of Interventions Version 5.0.1 (updated September 2008). The Cochrane Collaboration, 2008. Available from www.cochrane-handbook.org.

\section{Staheli 1987}

Staheli LT, Chew DE, Corbett M. The longitudinal arch: A survey of 802 feet in nomal children and adults. The Journal of Bone and Joint Surgery. American volume 1987;69:426-8.

\section{Sullivan 1999}

Sullivan JA. Pediatric flatfoot: evaluation and management. The Journal of the American Academy of Orthopaedic Surgeons 1999;7:
$44-53$.

van den Bergh 2003

Van den Bergh BR, de Rycke L. Measuring the multidimensional self-concept and global self-worth of 6- to 8-year-olds. Journal of Genetic Psychology 2003;164:201-25.

\section{Varni 1996}

Varni JW, Waldron SA, Gragg RA. Development of the Waldron/ Varni Pediatric Pain Coping Inventory. Pain 1996;67:141-50.

\section{Varni 2002}

Varni JW, Seid M, Knight TS, Szer JS. The PedsQL in pediatric rheumatology: Reliability, validity, and responsiveness of the Pediatric Quality of Life Inventory, Generic Core Scales and rheumatology module. Arthritis and Rheumatism 2002;46:714-25.

\section{Volpon 1994}

Volpon JB. Footprint analysis during growth period. Journal of Pediatric Orthopaedics 1994;14:83-5.

* Indicates the major publication for the study 
CHARACTERISTICS OF STUDIES

\section{Characteristics of included studies [ordered by study ID]}

Powell 2005

\begin{tabular}{ll}
\hline Methods & Randomised controlled clinical trial \\
\hline Participants & $\begin{array}{l}\text { Location: USA. Southern Californian children's hospitals, San Diego. Assessment Period: } \\
\text { 3-months. Recruitment: } 48 \text { recruited with } 48 \text { meeting criteria. Inclusion criteria: diag- } \\
\text { nosed juvenile chronic arthritis; over } 5 \text { years old, active foot disease, history of foot pain } \\
\text { over } 1 \text { month, able to walk } 50 \text { metres, stable medications. Exclusion criteria: previous } \\
\text { use of shoe inserts, joint injections in last } 6 \text { months, osseous anomaly. }\end{array}$ \\
\hline
\end{tabular}

\begin{tabular}{l|l} 
Interventions & $\begin{array}{l}\text { Group A: custom-made semi-rigid foot orthoses. Group B: prefabricated foot orthoses. } \\
\text { Group C: new athletic footwear with a medial longitudinal arch and shock-absorbing } \\
\text { sole. }\end{array}$ \\
\hline Outcomes & $\begin{array}{l}\text { Outcomes measured at baseline and 3-months follow up } \\
\text { 1. Pain: Paediatric Pain questionnaire - VAS, } 0 \text { to } 10 \text { point VAS scale ( } 0=\text { less pain) } \\
\text { 2. Speed of ambulation using the Timed Walking evaluation } \\
\text { 3. Function: Foot Function index with } 3 \text { subscales - Activity Limitation, Foot Pain, } \\
\text { Disability, } 0 \text { to } 100 \text { point scale }(0=\text { better function) } \\
\text { 4. Child health-related quality of life: Physical Functioning subscale of Paediatric } \\
\text { Quality of Life Inventory, } 0 \text { to } 100 \text { point scale }(0=\text { poorer function) }\end{array}$ \\
\hline Notes & $\begin{array}{l}\text { Pain reported in the trial using two instruments (Pediatric pain questionnaire and Foot } \\
\text { Pain subscale of the Foot Function index); for this review we extracted data using the } \\
\text { Pediatric Pain questionnare for the analysis of pain. }\end{array}$ \\
\hline
\end{tabular}

Risk of bias

\begin{tabular}{l|l|l}
\hline Item & Authors' judgement & Description \\
\hline Adequate sequence generation? & Unclear & $\begin{array}{l}\text { Quote: '...each subject was randomly placed } \\
\text { [using] a predetermined numbered placement } \\
\text { card... } \\
\text { Comment: method of generating random se- } \\
\text { quence unclear from published report }\end{array}$ \\
\hline Allocation concealment? & Unclear & $\begin{array}{l}\text { Comment: report states sealed envelopes were } \\
\text { used, but insufficient information to determine } \\
\text { if this was adequate to conceal treatment from } \\
\text { investigators }\end{array}$ \\
\hline $\begin{array}{l}\text { Blinding? } \\
\text { All outcomes }\end{array}$ & Yes & $\begin{array}{l}\text { Outcome assessor was blinded; participants were } \\
\text { not }\end{array}$ \\
\hline $\begin{array}{l}\text { Incomplete outcome data addressed? } \\
\text { All outcomes }\end{array}$ & Yes & $\begin{array}{l}\text { n=47 enrolled, } 7 \text { lost to follow up, unlikely to } \\
\text { bias outcomes }\end{array}$ \\
\hline
\end{tabular}


Powell 2005 (Continued)

\begin{tabular}{|c|c|c|}
\hline Free of selective reporting? & Yes & $\begin{array}{l}\text { All outcomes that the triallists measured were re- } \\
\text { ported }\end{array}$ \\
\hline Free of other bias? & Yes & \\
\hline
\end{tabular}

\section{Wenger 1989}

Methods

Participants

Interventions

Outcomes
Single blinded, randomised clinical trial

Location: USA. Texas Scottish Rite Hospital Flatfoot Clinic, Dallas. Assessment Period: 1978-1984. 131 children recruited with 129 meeting the criteria, 98 provided outcome data. Inclusion criteria: 1 to 6 years old and flexible flat feet. Exclusion criteria: neurological condition (cerebral palsy or muscular disease), excessive laxity (Down or EhlersDanlos syndrome) or previous treatment with foot orthoses or corrective footwear.

Group A: orthopaedic shoes. Group B shoes with Thomas heel, long medial counter, navicular pad. Group C: Helfet heel cup with shoes that included Thomas heel and long medial counter. Group D: UCBL custom-moulded foot orthoses.

Outcomes measured at baseline and 6-monthly intervals for 3 years

Radiographs: talus and sole of foot, talocalcaneal and talo first metatarsal angle, graded to measure clinical improvement in the appearance of the foot, compared with baseline radiograph, on a 1 to 4 scale, (1=greatly improved; 2 = improved; $3=$ no change; $4=$ worse)

UCBL: University of California Biomechanics Laboratory

\section{Risk of bias}

\begin{tabular}{|c|c|c|}
\hline Item & Authors' judgement & Description \\
\hline Adequate sequence generation? & Unclear & Not described \\
\hline Allocation concealment? & Unclear & Not described \\
\hline $\begin{array}{l}\text { Blinding? } \\
\text { All outcomes }\end{array}$ & Yes & $\begin{array}{l}\text { Outcome assessor was blinded; participants } \\
\text { were not }\end{array}$ \\
\hline $\begin{array}{l}\text { Incomplete outcome data addressed? } \\
\text { All outcomes }\end{array}$ & No & $\begin{array}{l}\mathrm{n}=31 \text { participants were excluded from anal- } \\
\text { ysis as they were lost to follow up, mostly } \\
\text { due to 'non-compliance'; the triallists do not } \\
\text { report which treatment these exclusions re- } \\
\text { ceived, and this may have biased the results } \\
\text { of the study }\end{array}$ \\
\hline Free of selective reporting? & Yes & All outcomes reported \\
\hline Free of other bias? & Yes & \\
\hline
\end{tabular}


Whitford 2007

\begin{tabular}{|c|c|c|}
\hline Methods & \multicolumn{2}{|c|}{ Single blinded, randomised clinical trial } \\
\hline Participants & \multicolumn{2}{|c|}{$\begin{array}{l}\text { Location: South Australia. University of South Australia, Adelaide. Assessment Period } \\
12 \text { months. } 672 \text { children recruited with } 178 \text { meeting the criteria. Inclusion criteria: aged } \\
7-11 \text { years, with bilateral excessive foot pronation. Exclusion criteria: unilateral flexible } \\
\text { excessive foot pronation, history of lower limb surgery, any neuromuscular condition or } \\
\text { previous treatment with foot orthoses or corrective footwear. }\end{array}$} \\
\hline Interventions & \multicolumn{2}{|c|}{$\begin{array}{l}\text { Group A: custom-made semi-rigid foot orthoses. Group B prefabricated semi-rigid foot } \\
\text { orthoses. Group C: no treatment. }\end{array}$} \\
\hline Outcomes & \multicolumn{2}{|c|}{$\begin{array}{l}\text { Outcomes measures at baseline and } 3 \text { and } 12 \text { months } \\
\text { 1. Pain using the Child Form of Varni Thompson Paediatric Child questionnaire, } \\
\text { VAS } \\
\text { 2. Motor proficiency using the Bruninks Oseretsky Test } \\
\text { 3. Exercise efficiency using the maximal oxygen shuttle run test to evaluate exercise } \\
\text { proficiency } \\
\text { 4. Self-perception using the Self Perception Profile for Children }\end{array}$} \\
\hline Notes & \multicolumn{2}{|c|}{$\begin{array}{l}\text { Secondary outcomes measured included ligamentous laxity, tight calf muscles and body } \\
\text { mass index. }\end{array}$} \\
\hline \multicolumn{3}{|l|}{ Risk of bias } \\
\hline Item & Authors' judgement & Description \\
\hline Adequate sequence generation? & Yes & Computer-generated sequence used \\
\hline Allocation concealment? & Unclear & Not described \\
\hline $\begin{array}{l}\text { Blinding? } \\
\text { All outcomes }\end{array}$ & Yes & Outcome assessor blinded; participants not \\
\hline $\begin{array}{l}\text { Incomplete outcome data addressed? } \\
\text { All outcomes }\end{array}$ & Yes & Drop-outs small and fairly even across groups \\
\hline Free of selective reporting? & Yes & $\begin{array}{l}\text { All outcomes measured by the triallists were } \\
\text { reported }\end{array}$ \\
\hline Free of other bias? & No & $\begin{array}{l}\text { Pain was measured using a continuous mea- } \\
\text { sure, but reported as dichotomised data; thus } \\
\text { the measure may be insensitive, and may un- } \\
\text { derestimate the treatment benefit }\end{array}$ \\
\hline
\end{tabular}




\section{Characteristics of excluded studies [ordered by study ID]}

\begin{tabular}{|c|c|}
\hline Bahler 1986 & The study is a report and is not an RCT or controlled clinical trial. \\
\hline Battaglia 1988 & $\begin{array}{l}\text { The study is not an RCT. The paper discuss the results of two case-series, one of } 39 \text { and the other } 52 \text { children } \\
\text { with pes planus recruited in two different hospitals. The intervention is foot orthoses designed to support. }\end{array}$ \\
\hline Bleck 1977 & $\begin{array}{l}\text { The study was a comparative study between foot orthoses (UCBL) and a heel cup (Helfet heel seat). The study was } \\
\text { non- randomised and the outcome measures were radiographs (plantarflexion angle of talus; calcaneal dorsiflexion } \\
\text { angle and the calcaneo-talar divergence angle). }\end{array}$ \\
\hline Bordelon 1980 & $\begin{array}{l}\text { This was a non-randomised prospective clinical trial of } 50 \text { children. The participants were given a foot orthoses } \\
\text { in specialised orthopaedic footwear. The outcome measures used included wear time, ankle dorsiflesion, foot } \\
\text { abduction and radiographs (lateral talometatarsal angle). }\end{array}$ \\
\hline Camin 2004 & This study was relating to metatarsus varus and was therefore excluded. \\
\hline Capasso 1993 & $\begin{array}{l}\text { This was a non-randomised clinical trial comparing a traditional foot orthoses with a new type of dynamic varus } \\
\text { foot orthoses. }\end{array}$ \\
\hline Gould 1989 & $\begin{array}{l}\text { This was a quasi-randomised clinical trail. The randomisation process was poorly described and the results were } \\
\text { written in percentages. No means or standard deviations described }\end{array}$ \\
\hline Jay 1995 & $\begin{array}{l}\text { This was a non-randomised prospective clinical trial of } 50 \text { children. The participants were assessed by comparing } \\
\text { the resting calcaneal stance position and the neutral calcaneal stance position. }\end{array}$ \\
\hline Kilmartin 1994 & $\begin{array}{l}\text { This is an RCT but only deals with the consequences of pes planus, hallux valgus. Although foot orthoses were } \\
\text { prescribed the study did not meet the inclusion criteria for this review. }\end{array}$ \\
\hline Mereday 1972 & $\begin{array}{l}\text { This was a non-randmised clinical trial of } 10 \text { children over } 2 \text { years. The outcome measures incuded wear time, ob- } \\
\text { servation of the posterior aspect of the calcaneum, arch height and radiographs (talocrural and talo-first metatarsal } \\
\text { angle). }\end{array}$ \\
\hline Niedzielski 1993 & Not a randomsied controlled trial. \\
\hline Redmond 2000 & This was a study pertaining to the use of a gait-plate relating to in-toeing gait. \\
\hline
\end{tabular}


DATA AND ANALYSES

Comparison 1. Custom-made orthoses versus shoes only

\begin{tabular}{lcccc} 
Outcome or subgroup title & $\begin{array}{c}\text { No. of } \\
\text { studies }\end{array}$ & $\begin{array}{c}\text { No. of } \\
\text { participants }\end{array}$ & Statistical method & Effect size \\
\hline 1 Pain at 3 months (10 point VAS) & 1 & & Mean Difference (IV, Random, 95\% CI) & Totals not selected \\
\hline
\end{tabular}

Comparison 2. Custom-made orthoses versus prefabricated orthoses

\begin{tabular}{|c|c|c|c|c|}
\hline Outcome or subgroup title & $\begin{array}{l}\text { No. of } \\
\text { studies }\end{array}$ & $\begin{array}{c}\text { No. of } \\
\text { participants }\end{array}$ & Statistical method & Effect size \\
\hline 1 Pain at 3 months (10 point VAS) & 1 & & Mean Difference (IV, Random, 95\% CI) & Totals not selected \\
\hline
\end{tabular}

Comparison 3. Prefabricated orthoses versus shoes

\begin{tabular}{lcccc} 
Outcome or subgroup title & $\begin{array}{c}\text { No. of } \\
\text { studies }\end{array}$ & $\begin{array}{c}\text { No. of } \\
\text { participants }\end{array}$ & Statistical method & Effect size \\
\hline 1 Pain at 3 months (10 point VAS) & 1 & & Mean Difference (IV, Random, 95\% CI) & Totals not selected \\
\hline
\end{tabular}

\section{Analysis I.I. Comparison I Custom-made orthoses versus shoes only, Outcome I Pain at 3 months (10 point VAS).}

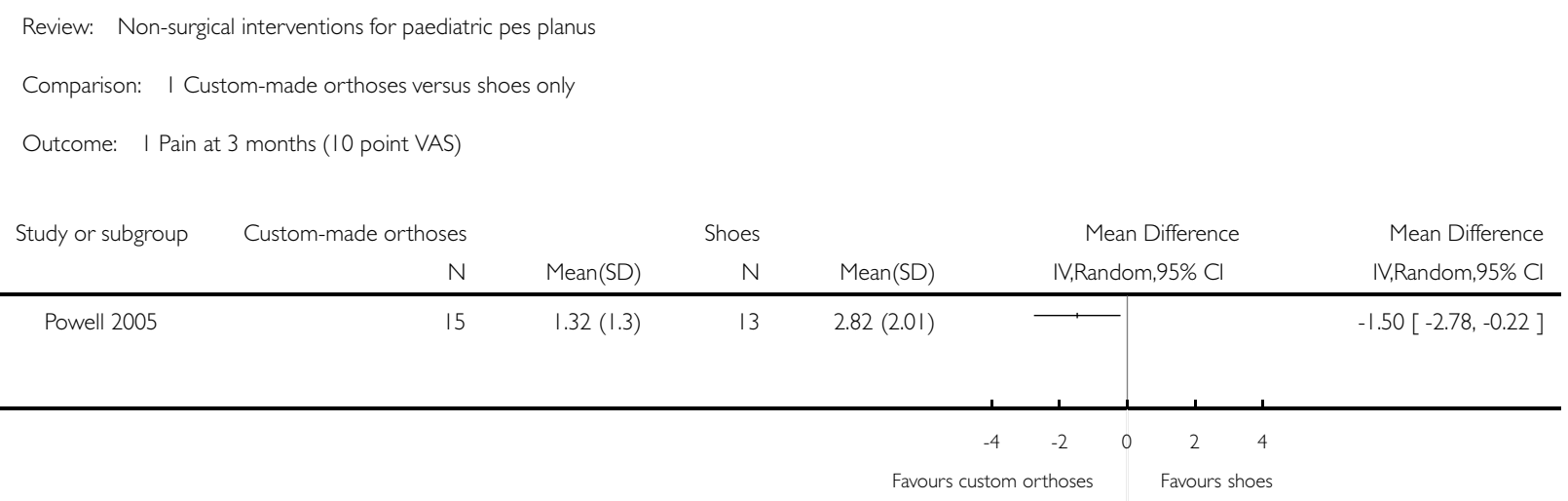


Analysis 2.I. Comparison 2 Custom-made orthoses versus prefabricated orthoses, Outcome I Pain at 3 months ( 10 point VAS).

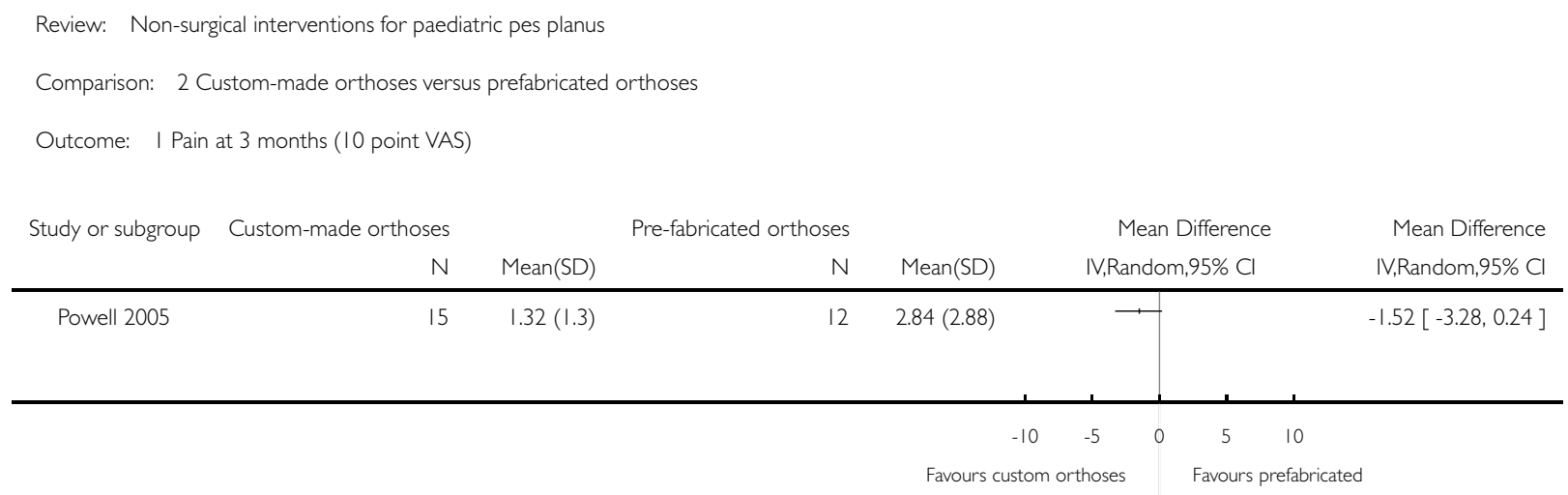

Analysis 3.I. Comparison 3 Prefabricated orthoses versus shoes, Outcome I Pain at 3 months ( 10 point VAS).

Review: Non-surgical interventions for paediatric pes planus

Comparison: 3 Prefabricated orthoses versus shoes

Outcome: I Pain at 3 months ( 10 point VAS)

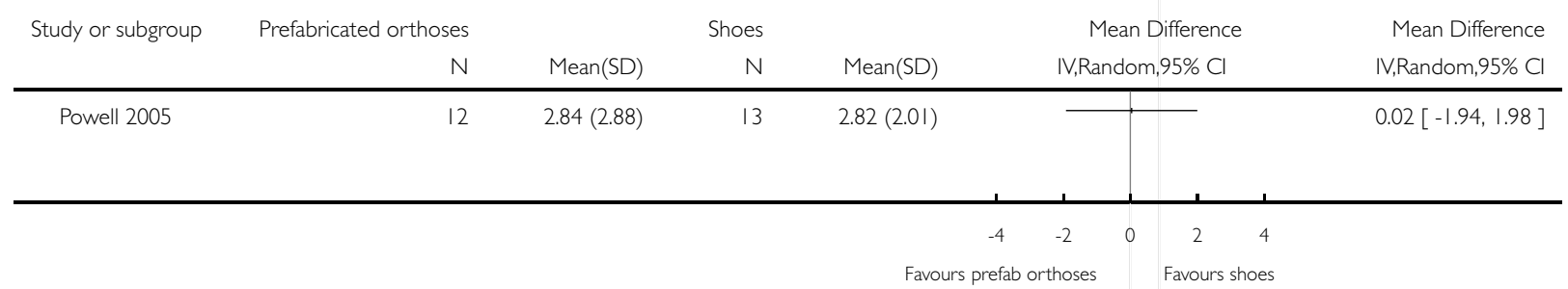




\section{A P P E N D I CES}

\section{Appendix I. MEDLINE search strategy}

1. exp flatfoot/

2. flat foot\$.mp.

3. flatfoot\$.mp.

4. flat feet.mp.

5. flatfeet.mp.

6. pes planus.mp.

7. painful foot.mp.

8. pes planovalgus.mp.

9. posterior tibial tendon dysfunction.mp.

10. subtalar.mp.

11. (sub\$ adj talar).mp.

12. calcane\$.mp.

13. heel bone\$.mp.

14. medical arch $\$ 2 . \mathrm{mp}$.

15. or/1-14

16. exp musculoskeletal diseases/

17. exp neuromuscular diseases/

18. exp nervous system diseases/

19. ehlers-danlos.mp.

20. down $\$$ syndrome.mp.

21. trisomy.mp.

22. mongolism.mp.

23. inflammatory arthritis.tw.

24. (juvenile adj3 arthritis).tw.

25. or/16-24

26. exp diabetes mellitus, type $1 /$

27. (diabet\$ or IDDM).tw.

28. 26 or 27

29. exp diabetes insipidus/

30. mellitus.tw.

31. 29 not $(26$ or 30$)$

32. (diabet $\$$ adj (insipidus not mellitus)).tw.

33. 31 or 32

34. 28 not 33

35. joint instability.sh.

36. ligament $\$$ laxity.mp.

37. pronat $\$ . \mathrm{mp}$.

38. malalignment.mp.

39. or $/ 35-38$

40. or $/ 25,34,39$

41. 15 and 40

42. randomized controlled trial.pt.

43. controlled clinical trial.pt.

44. randomized.ab.

45. placebo.ab.

46. drug therapy.fs.

47. randomly.ab.

48. trial.ab.

49. groups.ab. 
50. or/42-49

51. (animals not (humans and animals)).sh.

52. 50 not 51

53. 41 and 52

54. limit 53 to ("infant (1 to 23 months)" or "preschool child (2 to 5 years)" or "child (6 to 12 years)" or "adolescent (13 to 18 years)")

55. child.mp.

56. children.mp.

57. childhood.mp.

58. infant\$.mp.

59. teenag\$.mp.

60. adolescen\$.mp.

61. paediatric.mp.

62. pediatric.mp.

63. or $/ 55-62$

64. 53 and 6

65. 54 or 64

\section{Appendix 2. EMBASE search strategy}

1. Flatfoot/

2. flat foot\$.mp.

3. flatfoot\$.mp.

4. flat feet.mp.

5. flatfeet.mp.

6. pes planus.mp.

7. painful foot.mp.

8. pes planovalgus.mp.

9. posterior tibial tendon dysfunction.mp.

10. subtalar.mp.

11. (sub\$ adj talar).mp.

12. calcane\$.mp.

13. heel bone $\$ . m p$.

14. medical arch $\$ 2 . \mathrm{mp}$.

15. or/1-14

16. exp Musculoskeletal Disease/

17. exp Neuromuscular Disease/

18. exp Neurologic Disease/

19. ehlers-danlos.mp.

20. down\$ syndrome.mp.

21. trisomy.mp.

22. mongolism.mp.

23. inflammatory arthritis.tw.

24. (juvenile adj3 arthritis).tw.

25. or/16-24

26. Insulin Dependent Diabetes Mellitus/

27. (diabet\$ or IDDM).tw.

28. 26 or 27

29. exp Diabetes Insipidus/

30. mellitus.tw.

31. 29 not ( 26 or 30$)$

32. (diabet $\$$ adj (insipidus not mellitus)).tw.

Non-surgical interventions for paediatric pes planus (Review)

Copyright (@) 2010 The Cochrane Collaboration. Published by John Wiley \& Sons, Ltd. 


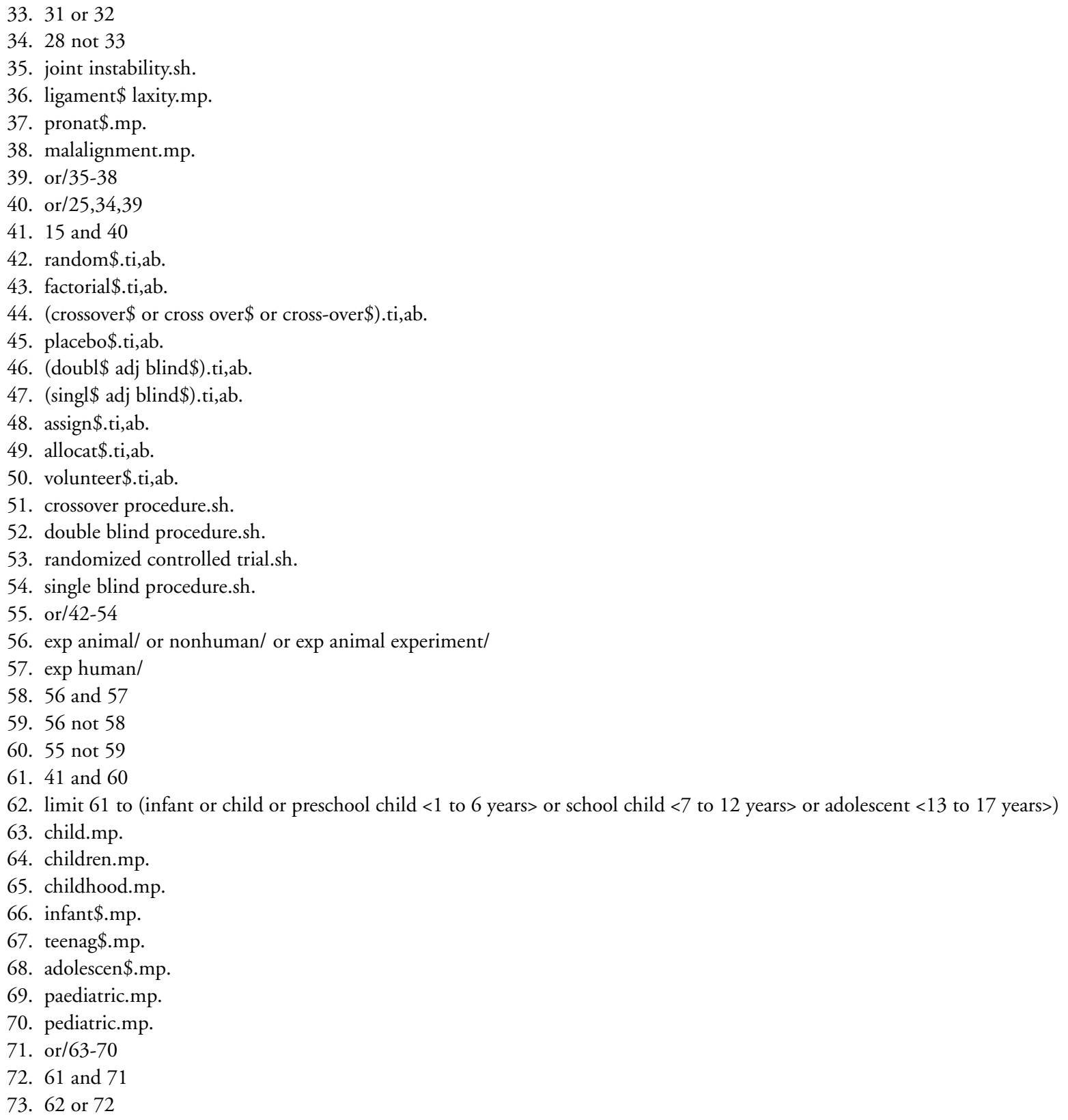

\title{
Appendix 3. CENTRAL search strategy
}

\author{
\#1 MeSH descriptor Flatfoot explode all trees \\ \#2 flat next foot*:ti,ab \\ \#3 flatfoot:ti,ab \\ \#4 flat next feet:ti,ab \\ \#5 flatfeet:ti,ab \\ \#6 pes next planus:ti,ab \\ \#7 painful next foot:ti,ab \\ \#8 pes next planovalgus:ti,ab
}




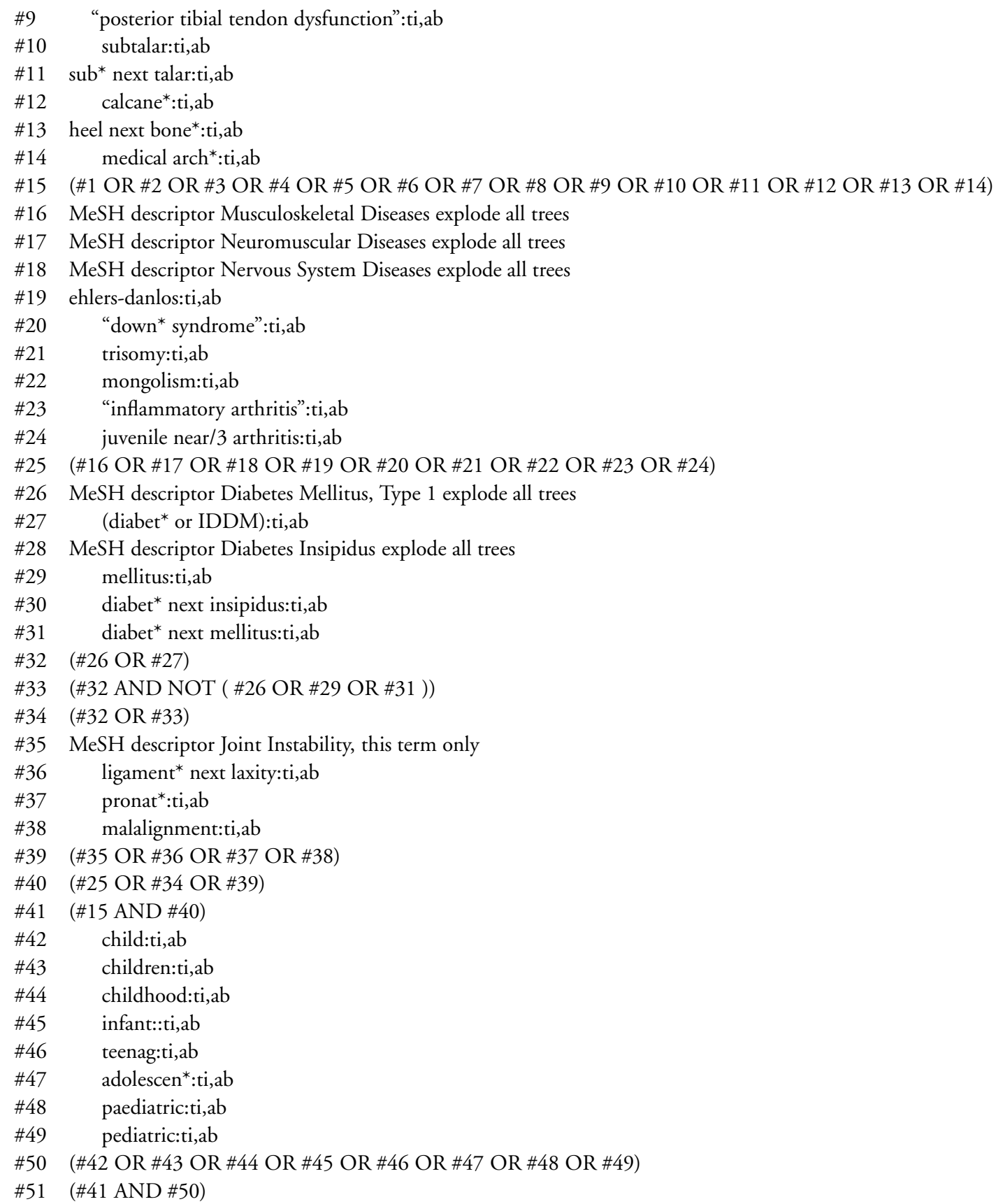




\section{Appendix 4. CINAHL search strategy}

S40 S26 and S39

S39 S27 or S28 or S29 or S30 or S31 or S32 or S33 or S34 or S35 or S36 or S37 or S38

S38 TI Allocat* random* or AB Allocat* random*

S37 (MH “Quantitative Studies")

S36 (MH "Placebos")

S35 TI Placebo* or AB Placebo*

S34 TI Random* allocat* or AB Random* allocat*

S33 (MH "Random Assignment")

S32 TI Randomi?ed control* trial* $^{*}$ or AB Randomi?ed control* trial $^{*}$

$\mathrm{S} 31 \mathrm{AB}$ singl* blind $^{*}$ or $\mathrm{AB}$ singl* mask $^{*}$ or $\mathrm{AB}$ doub* blind* $^{*}$ or $\mathrm{AB}$ doubl* mask* or $\mathrm{AB}$ trebl* blind* ${ }^{*}$ or $\mathrm{AB}$ trebl* mask ${ }^{*}$ or $\mathrm{AB}$ tripl* blind* or $\mathrm{AB}$ tripl$^{*}$ mask*

S30 TI singl* blind* or TI singl* mask* or TI doub* blind* or TI doubl* mask* or TI trebl* blind* or TI trebl* mask* or TI tripl* blind* or TI tripl* mask*

S29 TI clinical ${ }^{*}$ trial $^{*}$ or $\mathrm{AB}$ clinical* trial* $^{*}$

S28 PT clinical trial

S27 (MH "Clinical Trials+")

$\mathrm{S} 26 \mathrm{~S} 5$ and S25

S25 S10 or S19 or S24

S24 S20 or S21 or S22 or S23

S23 TI malalignment or AB malalignment

S22 TI pronat* or AB pronat*

S21 TI ligament* laxity or AB ligament* laxity

S20 (MH “Joint Instability+")

S19 S13 not S18

S18 $\mathrm{S} 16$ or $\mathrm{S} 17$

S17 TI diabet* insipidus or AB diabet* insipidus not TI diabet* mellitus or AB diabet* mellitus

S14 not (S11 or S15)

S15 ti mellitus or ab mellitus

S14 (MH "Diabetes Insipidus")

S13 S11 or S12

S12 TI diabet* or AB diabet* or TI IDDM or AB IDDM

S11 (MH "Diabetes Mellitus, Insulin-Dependent")

$\mathrm{S} 10 \mathrm{~S} 6$ or $\mathrm{S} 7$ or $\mathrm{S} 8$ or $\mathrm{S} 9$

S9 TI ehlers-danlos or AB ehlers-danlos or TI down* syndrome or $\mathrm{AB}$ down* syndrome or TI trisomy or AB trisomy or TI mongolism or $\mathrm{AB}$ mongolism or TI inflammatory arthritis or $\mathrm{AB}$ inflammatory arthritis or TI juvenile $\mathrm{N} 3$ arthritis or $\mathrm{AB}$ juvenile $\mathrm{N} 3$ arthritis

S8 (MH "Nervous System Diseases+") S7 (MH "Neuromuscular Diseases+")

S6 (MH "Musculoskeletal Diseases+") S5 S1 or S2 or S3 or S4

S4 TI subtalar or $\mathrm{AB}$ subtalar or TI sub* adj talar or $\mathrm{AB}$ sub* adj talar or TI calcane* or $\mathrm{AB}$ calcane* or TI heel bone* or $\mathrm{AB}$ heel bone* or TI medical arch* or AB medical arch* Search modes - Boolean/Phrase S3 TI pes planus or AB pes planus or TI painful foot or $\mathrm{AB}$ painful foot or $\mathrm{TI}$ pes planovalgus or $\mathrm{AB}$ pes planovalgus or TI posterior tibial tendon dysfunction or $\mathrm{AB}$ posterior tibial tendon dysfunction Search S2 TI flat foot* or AB flat foot* or TI flatfoot* or AB flatfoot* or TI flat feet or AB flat feet or TI flatfeet or AB flatfeet

S1 (MH "Flatfoot") 


\section{Appendix 5. Dissertation Abstracts}

(flatfoot) OR (flat foot*) OR (flatfoot*) OR (flat feet) OR (flatfeet) OR (pes planus) OR (painful foot) in Citation and Abstract

\section{H I S T O R Y}

Protocol first published: Issue 1, 2007

Review first published: Issue 7, 2010

\section{CONTRIBUTIONSOFAUTHORS}

$\mathrm{KR}$ and RA conceived and designed the review. KR collected and inputted the data. KR and AE compiled the data and drafted the manuscript and RA contributed to the drafting of the manuscript. All authors read and approved the final manuscript.

\section{DECLARATIONSOF INTEREST}

None known

\section{SOURCES OF SUPPORT}

\section{Internal sources}

- University of Teesside, UK.

- University of Central England, UK.

- University of South Australia, Australia.

\section{External sources}

- No sources of support supplied

\section{DIFFERENCES BETWEEN PROTOCOLANDREVIEW}

'Risk of bias' and 'Summary of findings' tables were not described in the protocol but were included in the review, in accordance with current Cochrane Collaboration guidance. 